\title{
Las desigualdades sociales en salud: un reto para las políticas públicas ${ }^{1}$
}

\section{Javier Segura del Pozo}

Servicio de Prevención y Promoción de la Salud, Instituto de Salud Pública, Madrid Salud, Ayuntamiento de Madrid.

<javier.seguradelpozo@gmail.com>

Gero eta ebidentzia gehiagok jasotzen dutenez, milaka gaixotasun eta heriotza goiztiar ekidingo lirateke, modu esklusibo batean osasunzerbitzuetan zentratu ordez, determinante sozialetan eskuartzeak bideratuko bagenitu. Horretaz gain, bidegabeko eta saihets daitezkeen osasun-mailako desberdintasunak daude, eta berauen iturria izaten da gizarte-maila, generoa, etnia, migrazio-egoera edo enplegua. Horiei esaten diegu direla osasun-arloko gizartedesberdintasunak. Artikulu honetan garatzen dugu kontzeptua, azaltzen ditugu beronen genesirako eredu kontzeptual batzuek, azterlan historiko batzuek jasotzen ditugu, laburbiltzen ditugu gaur egungo polemika batzuek, eta pintzelkada batzuen bidez jasotzen ditugu osasun-arloko desberdintasun-maila gutxiarazteko oraintsu abian diren europar politikak. Bertan nabarmentzen ditugu joandako hamarkadetan garrantzitsuen izandako espainiar azterlan eta ekimenak (Euskadikoak barne direlarik), eta proposatzen ditugu etorkizunerako ikerkuntza- eta ekimenildoak. Azkenik, gogoeta burutzen da errealitate konplexu hori osoki ulertzeko epidemiologia sozialaren mugen inguruan, eta aldezten da "epidemiologia mestizo" bat.

\section{GAKO-HITZAK:}

Osasun-arloko gizarte-desberdintasunak, osasunarloko determinante sozialak, epidemiologia soziala, medikuntza soziala, politika publikoak.
Cada vez hay más evidencias de que se podrían evitar miles de casos de enfermedades y muertes prematuras si interviniéramos en sus determinantes sociales, en vez de centrarnos exclusivamente en los servicios sanitarios ('salud no es sinónimo de sanidad'). También de que existen escandalosas diferencias en salud, que son injustas y evitables, por tener su origen en la clase social, género, etnia, situación migratoria o de empleo. Es lo que denominamos desigualdades sociales en salud. En este artículo desarrollamos el concepto, exponemos algunos modelos conceptuales sobre su génesis, presentamos algunos estudios históricos, resumimos algunas polémicas actuales y damos alguna pincelada sobre las políticas europeas recientes para reducir las desigualdades sociales en salud. Señalamos los estudios e iniciativas españolas más relevantes de las últimas décadas (incluidas las de Euskadi) y proponemos líneas de investigación y acción futuras. Finalmente, se reflexiona sobre los límites de la epidemiología social para captar esta compleja realidad, abogándose por una 'epidemiología mestiza'.

\section{PALABRAS ClaVe:}

Desigualdades sociales en salud, determinantes sociales de la salud, epidemiología social, medicina social, políticas públicas. 


\section{1. ¿Qué es la epidemiología social?}

Los estudios de desigualdades sociales en salud intentan mostrar y demostrar la relación entre los estados de salud y la pertenencia a un estrato o condición social. La mayoría de estos estudios se pueden situar en el campo bautizado como epidemiología social. Es decir, utilizan los conceptos y las herramientas de la epidemiología, pero se interesan especialmente por la relación de la salud con el contexto social. Aunque el término 'epidemiología' ya lleva implícito el concepto social (la traducción literal de epi-demos es 'sobre el pueblo'), a mediados del siglo XX hubo que añadirle la palabra 'social' a este enfoque de la epidemiología para diferenciarla de la epidemiología dominante. Ésta centraba sus intereses en los factores individuales, especialmente en los llamados hábitos de salud o estilos de vida (por ejemplo, fumar, llevar una vida sedentaria, tener una alimentación inadecuada), o en los conocimientos asociados a las decisiones clínicas (epidemiología clínica), principalmente la prescripción de medicamentos u otros procedimientos terapéuticos.

La epidemiología social tiene un precedente: la medicina social. La medicina social fue un fenómeno fundamentalmente urbano e industrial, que tuvo su origen en la preocupación de los gobernantes por 'las clases peligrosas', concentradas en algunos espacios de las ciudades, fruto de la atracción del proceso de industrialización.

\section{El modelo de la caja negra}

La revolución bacteriológica (que tuvo a Robert Koch, descubridor del microorganismo de la tuberculosis, el bacilo de Koch, como uno de sus referentes) infundió la idea de que la atención médica, a través del progreso de la farmacopea y de la tecnología sanitaria, erradicaría las principales enfermedades. La anterior preocupación de la medicina social por el diseño de las ciudades, el saneamiento de los barrios obreros, la alimentación de sus hijos, las exposiciones a tóxicos en los lugares de trabajo o la jornada laboral pasaba a un segundo plano, y se consideraba una cuestión que apenas entraba en el campo de batalla de la medicina, sino en el de las luchas sociales.

Pero el avance de las enfermedades crónicas puso en crisis el paradigma mecanicista y bacteriológico imperante en la medicina. Enfermedades como la diabetes, el infarto de miocardio o el cáncer no podían ser explicadas desde el modelo de las enfermedades infecciosas. No se podía aislar e identificar un agente único externo responsable de la enfermedad (por ejemplo, una bacteria) y no había, por lo tanto, una terapéutica específica dirigida a eliminar ese agente externo. La medicina fracasaba frente a estas enfermedades. Sólo podía poner parches para aliviarlas o retrasar su desenlace. Se necesitaba un nuevo modelo causal para explicar la pujanza de estas enfermedades en los países desarrollados.
La epidemiología dominante proporcionó este modelo: el de la multicausalidad, 'la caja negra' y los riesgos individuales. La teoría de la multicausalidad propugnaba que las enfermedades crónicas tenían múltiples factores causales. Hasta ahí bien. Pero el problema es que se desentendía de explicar la relación de los factores entre sí. Todos eran considerados en el mismo nivel de jerarquía. Los factores socioeconómicos (pobreza, paro) se situaban al mismo nivel que los hábitos (fumar, sedentarismo) o las características fisiológicas (hipertensión arterial) o bioquímicas (hipercolesterolemia). Todos los factores individuales eran medidos y metidos en la caja, donde la relación entre unos y otros no era considerada importante y permanecía desconocida (Figura 1). Lo que salía de la caja era la enfermedad, que era medida y comparada con las medidas de los factores de riesgo individuales.

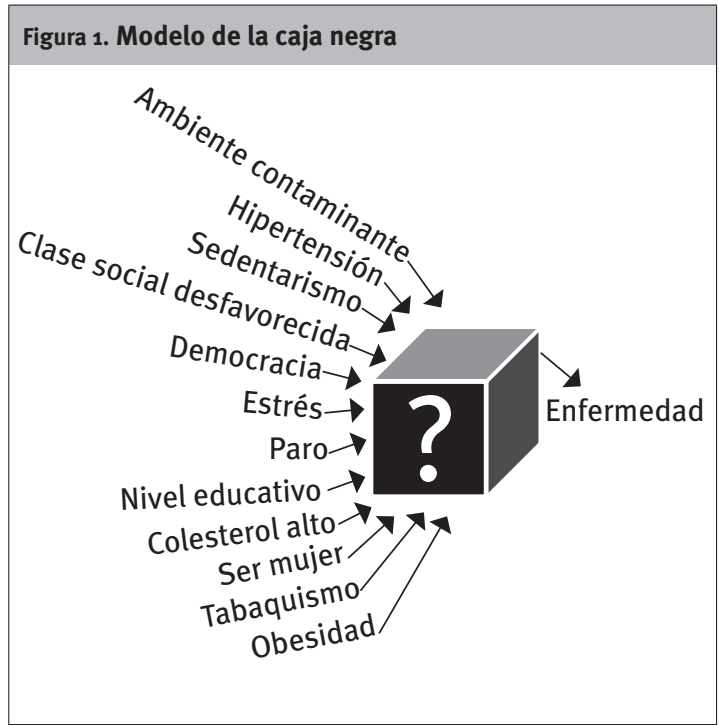

Fuente: Segura del Pozo (2013: 32).

El desarrollo de métodos estadísticos de análisis multivariante y de la informática favorecieron estos estudios complejos. Se impulsó así una cultura epidemiológica centrada en el dominio de los métodos, cada vez más complejos y sofisticados, y una fascinación por la estadística y los modelos matemáticos. Frente a ella, el pensamiento causal o la contextualización del problema a partir de lo colectivo y social (que se identifica con lo filosófico-especulativo o las ciencias sociales) y la aplicación del conocimiento para intervenir sobre las causas sociales que generan la enfermedad en la comunidad (más identificado con lo político) se consideraban elementos ajenos al campo de la epidemiología.

El riesgo era concebido como individual (originado en cada individuo, en vez de en el grupo o la sociedad de pertenencia) y no se cuestionaban los mecanismos de producción de la enfermedad (es decir, la relación entre las desigualdades económicas, la explotación o los mecanismos de dominación, con 
los factores socioeconómicos; y de éstos con los hábitos de salud o las características fisiológicas, bioquímicas o inmunitarias).

\section{3. ¿Dónde está la araña?}

En la década de los sesenta y setenta del siglo pasado, como rechazo al modelo imperante de la caja negra y la multicausalidad, aparecen los que ahora llamamos epidemiólogos sociales. En el mundo anglosajón, destacan nombres como Susser, Syme, Graham o Rose. Muchos de ellos incorporan modelos y métodos provenientes del campo de la sociología o la antropología. En Latinoamérica, la medicina social estuvo bien representada por muchos profesionales, como Hernán San Martín, Héctor Abad, Naomar de Almeida Filho, Cristina Laurell, Edmundo Grandes o Jaime Breihl.

Geoffrey Rose (1926-1993), en su libro La estrategia de la medicina preventiva (1994), desarrolla la teoría sobre la distribución del riesgo en las poblaciones. El riesgo individual de enfermar no puede considerarse aislado del riesgo de la población a la que se pertenece. Así, por ejemplo, el nivel de colesterol considerado 'normal' en la sociedad finlandesa es causa de alarma en Japón. La principal implicación de la teoría de Rose es que, en vez de preguntarnos por qué este individuo particular enferma, nos debemos preguntar por qué esta población tiene esta particular distribución de riego. Frente a las estrategias de prevención centradas en los grupos de alto riesgo ('estrategias de alto riesgo'), debemos promocionar 'estrategias poblacionales', dirigidas a cambiar los condicionantes estructurales de estos riesgos en la población.

La figura de Mervin Susser es un referente obligado en el mundo de la epidemiología social, siendo inseparable de la aportación de su mujer, Zena Stein (n. 1922). Activistas sociales y anti apartheid en la Sudáfrica de los años cuarenta, se autoexiliaron en Inglaterra (1956-1965), donde publicaron los primeros estudios a partir de los datos recogidos en Sudáfrica: epidemiología reproductiva (bajo peso, retraso mental, abortos espontáneos) y su relación con la estructura social. También elaboraron sus estudios considerando la exposición acumulativa a riesgos a lo largo de toda la vida (lifecourse epidemiology). En su libro Causal Thinking in the Health Sciences (Susser, 1991), Susser hace una distinción entre causa distante e inmediata de la enfermedad e introduce la perspectiva ecológica en la epidemiología. Abogaba por considerar diferentes niveles de organización (celular, orgánico, individual, grupal, social) a la hora del diseño y el análisis de datos en un estudio epidemiológico.

Entre los múltiples seguidores de Susser, destacaremos a Nancy Krieger, profesora de la Escuela de Salud Pública de Harvard. Nancy lleva muchos años dedicados a los estudios de desigualdades sociales en salud, especialmente enfocados a integrar las desigualdades de clase y género. Es una especialista de los estudios multinivel, y entre sus desarrollos teóricos destaca el artículo Epidemiology and the web of causation: Has anyone seen the spider?

(Krieger, 1994). En él, critica la teoría multicausal de la enfermedad, preguntándose que si existe una telaraña de causas (red causal), por qué no nos preguntamos dónde está la araña que ha tejido la tela, es decir, cuál es la causa última de la constelación de 'factores de riesgo'.

Latinoamérica tiene una fecunda historia de pioneros en medicina social o higiene social. Algunos son conocidos por sus libros de texto, como el chileno Hernán San Martín (1915-1943), salubrista y antropólogo social, cuya obra Salud y enfermedad (1995) fue una referencia para los salubristas que nos formamos a principios de los ochenta en España.

En el último cuarto del siglo XX, aparecieron en Latinoamérica varias concepciones críticas de la teoría y práctica epidemiológica. Gracias a proyectos colaborativos (realizados en torno a asociaciones como la Associação Brasileira de Saúde Coletiva [ABRASCO] o la Asociación Latinoamericana de Medicina Social [ALAMES], revistas como Medicina Social o el repositorio de revistas Scielo), que han permitido la difusión y el intercambio de experiencias, actualmente nos encontramos con un sólido polo de investigadores, estudios y prácticas de medicina social. Mencionaremos como ejemplos la epidemiología de las clases sociales (o la teoría de los perfiles epidemiológicos de clase) del Grupo de Quito (Edmundo Granda, Jorge Breilh); la epidemiología laboral (teoría del proceso de producción y salud) del grupo de la UAM-Xochimilco en México (Asa Cristina Laurell); o el movimiento de Salud Colectiva en Brasil, que se agrupó alrededor de $\mathrm{ABASCO}^{2}$, de la Escola Nacional de Saúde Pública Sergio Arouca-Fundação Oswaldo $\mathrm{Cruz}^{3}$ y de su revista Cadernos de Saúde Pública ${ }^{4}$. Naomar de Almeida-Filho es uno de los epidemiólogos más conocidos de este movimiento. Además de investigador, destaca por su profunda formación epistemológica (especialmente alimentada por los pensadores franceses, como Foucault, Castoriadis o Canguilhem), que le ha permitido hacer una interesantísima crítica del concepto de riesgo en epidemiología (Almeida-Filho, 2000) y un esfuerzo titánico de aproximación entre los métodos cuantitativos y cualitativos, entre el mundo de la estadística y el de la antropología. Su propuesta de epidemiología del modo de vida o etnoepidemiología constituye una fecunda aportación al pensamiento epidemiológico crítico.

\section{Los funcionarios como conejillos de indias: el estudio Whitehall}

Este renovado interés por buscar en lo social el origen de las enfermedades tuvo un notable desarrollo en la Gran Bretaña de las décadas de los setenta y ochenta, y está representado por un estudio y un

\footnotetext{
${ }^{2}\langle$ http://www.abrasco.org.br〉.

3 〈http://www.ensp.fiocruz.br〉.

${ }^{4}\langle$ http://www.ensp.fiocruz.br/csp/〉.
} 
informe que ya son referencias históricas y marcan un antes y un después en la epidemiología social: el estudio (o los estudios) Whitehall y el informe Black.

En el primero, se utilizan a los funcionarios londinenses como conejillos de Indias, intentando contestar a preguntas como: ¿quién tiene más riesgo de morir por infarto de miocardio: el estresado director general, cargado de responsabilidades, o el modesto y ocioso conserje del ministerio?; ¿se reducen las desigualdades sociales en salud a una cuestión de pobreza?; o ¿el gradiente social de salud se da también dentro de las clases medias, e incluso, dentro de las clases altas?

El estudio de Whitehall (Marmot et al., 1978) 5 fue un gigantesco trabajo de investigación que consistió en el seguimiento durante más de 10 años (1967-1982) del estado de salud de 17.500 funcionarios estatales (varones de entre 20 y 64 años) del complejo administrativo de Whitehall, en Londres. Se comprobó cómo las tasas de mortalidad (especialmente por enfermedades cardiovasculares coronarias como el infarto agudo de miocardio) eran mayores en los niveles inferiores de la escala jerárquica, en comparación con los niveles ejecutivos, cercanos al nivel político.
El estudio de Whitehall ${ }^{6}$, como otros estudios longitudinales 7 , muestra, sin los sesgos propios de los estudios transversales ${ }^{8}$, que tanto para las enfermedades coronarias como para todas las causas de muerte -excepto las debidas a enfermedades genitourinarias- hay un gradiente entre las diferentes clases ocupacionales (Gráfico 1). Así, el riesgo de morir va incrementándose a medida que se desciende en la escala laboral:

1. Personal de dirección y gerencia.

2. Personal técnico.

3. Personal administrativo.

4. Personal subalterno.

El estudio también señala que los funcionarios de las escalas inferiores mostraban claramente una mayor propensión a tener factores de riesgo para la salud, como la obesidad, el tabaquismo, menos tiempo de ocio, menos actividades físicas, más enfermedades de base, mayor tensión arterial, e, incluso, a tener una altura menor (vamos, que eran más bajos). La diferencia en el riesgo de morir se mantenía con el tiempo, y lo que era más sorprendente, ipersistía aunque se ajustara ${ }^{9}$ por los factores de riesgo antes mencionados!, como la obesidad, el sedentarismo, el hábito de fumar o los niveles altos de tensión

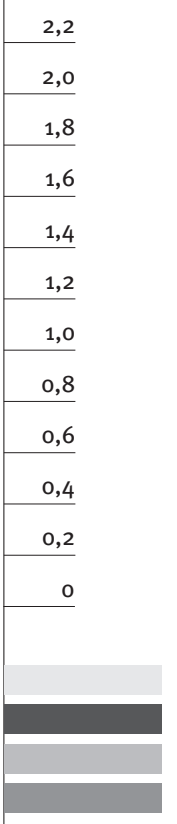

Personal de dirección y gerencia

Personal técnico

Personal administrativo

Personal subalterno

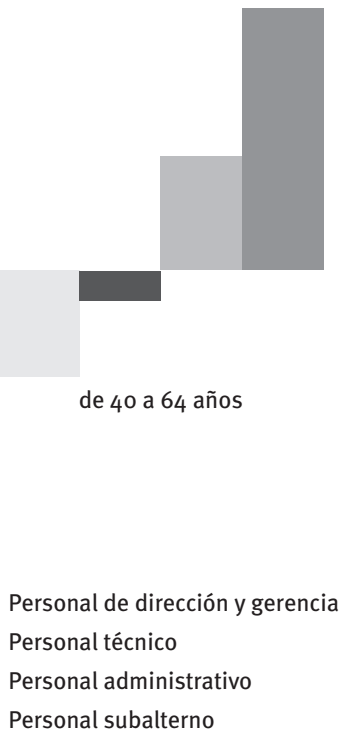

Fuente: Segura del Pozo (2013: 96).

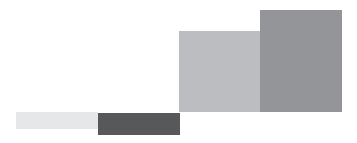

de 65 a 69 años

de 70 a 89 años

${ }^{6}$ Véase 〈http://en.wikipedia.org/wiki/Whitehall_Study〉.

${ }_{7}$ Aquellos que miden el estado de salud de un grupo de población a lo largo de un periodo de tiempo.

${ }^{8}$ Aquellos que miden el estado de salud en un momento determinado.

${ }^{9}$ Se excluyera su influencia. 
arterial, glucemia o colesterol. Una vez ajustado por estos factores, el riesgo de morir por enfermedades cardiovasculares era 2,1 veces mayor en los estratos bajos frente a los directivos. Es decir, la diferencia no podía justificarse sólo por malos hábitos de salud individuales (pues estos factores de riesgo individuales no explicaban más del $40 \%$ de la diferencia en la mortalidad).

El estudio también fue un intento de evitar algunos de los problemas del uso de la clase ocupacional como aproximador (proxy) a la clase social. Por ejemplo, el problema de la heterogeneidad de ocupaciones dentro de cada clase podía dar lugar a diferentes interpretaciones de los resultados, pero el estudio de Whitehall se concentraba en un sector productivo, el de la administración pública, con escasa heterogeneidad dentro de los grados ocupacionales y una clara división social entre grados.

\section{Desmontando dos mitos}

En cierta manera, se desmontó el mito de que los altos ejecutivos de la Administración, estresados y con la carga propia de la responsabilidad inherente al puesto, estaban desgastando su salud, mientras que los 'ociosos' conserjes y los simples administrativos con tareas rutinarias estaban menos sometidos a ese desgaste. Evidentemente, lo que el estudio ponía en evidencia era el riesgo diferencial de morir por pertenecer a clases sociales diferentes. Los altos puestos de la Administración eran más fácilmente accesibles a las clases altas o medias-altas, al igual que las escalas jerárquicas inferiores solían ser ocupadas por personas con menor nivel de estudios, como consecuencia de su origen de clase más humilde.

Otro mito que intentó desmontar el estudio es que el gradiente de salud en las sociedades industrializados era simplemente debido a la pobre salud de los más desfavorecidos, frente a la buena salud del resto de la sociedad. Al mostrar que había un gradiente de mortalidad entre los funcionarios británicos, ninguno de los cuales se encontraba entre los pobres en sentido absoluto (ni entre los más ricos de la sociedad), defendió la idea de que el gradiente en salud atraviesa toda la sociedad, desde lo más bajo a lo más alto ${ }^{10}$. Es la teoría del gradiente social.

\section{Salud no es un sinónimo de sanidad: el informe Black}

El informe Black (The Black Report), aparecido en el Reino Unido en 1980, demostraría de una forma sencilla, pero con gran solidez científica, que el riesgo de morir (antes de los 65 años) era mayor en las clases sociales más desfavorecidas. El estudio, dirigido por el presidente del Colegio de Médicos del Reino Unido, había sido encargado unos años antes por los laboristas, pero fue recibido por la nueva primera ministra conservadora, Margaret Thatcher. A su pesar, tuvo una amplia difusión mediática, con

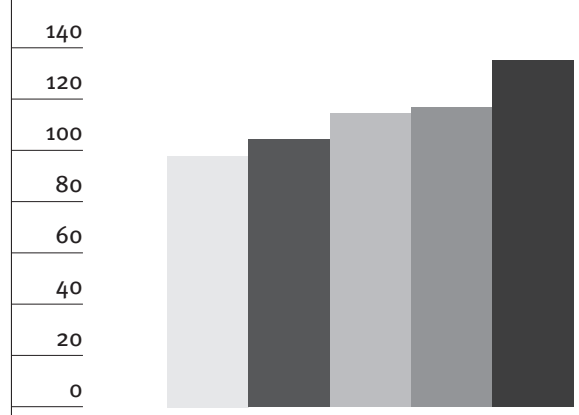

1951

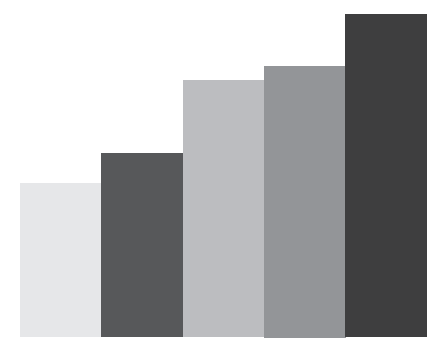

1961

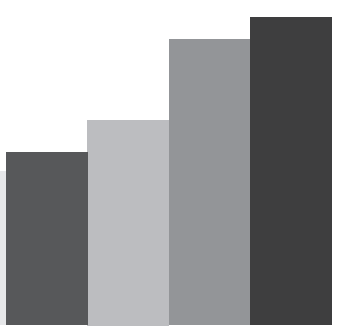

1971

I Profesional

II Intermedios

III Cualificados manuales y no manuales

IV Parcialmente cualificados

V No cualificados

Fuente: Segura del Pozo (2013: 96). 
una edición en libro de bolsillo (Black, 1982), y tambalearía la autocomplacencia de la sociedad británica sobre la equidad de su sistema de salud y políticas públicas.

Después de revisar las evidencias y estudios disponibles y los análisis realizados ad hoc para el informe, se concluía que en el Reino Unido había unas diferencias marcadas en las tasas de mortalidad de las clases ocupacionales (un aproximador de clase social), en ambos sexos y en todas las edades:

- Si aplicáramos las tasas de mortalidad (el riesgo de morir) de la clase I (profesionales y sus familiares) a las clases IV y V (trabajadores semicualificados y no cualificados, y sus familiares), entre 1972 y 1974 se habría salvado la vida de 74.000 personas menores de 65 años (incluyendo 10.000 niños).

- Lo que más escocía a los británicos era que el gradiente de clase era mayor que en otros países del entorno (incluida la tantas veces rival Francia!) y se había incrementado en las últimas décadas (Gráfico 2), a pesar de los cuarenta años de vida del modélico Servicio Nacional de Salud (National Health Service, NHS).

¿Qué es lo que se había hecho mal? Según el grupo de trabajo, gran parte del problema estaba fuera del alcance del NHS: factores socioeconómicos como ingresos, paro, medioambiente, educación, vivienda, transporte y estilos de vida, que afectan a la salud, habían quedado fuera del ámbito de las políticas de salud. Además, las 'clases manuales' (con ocupaciones manuales) estaban haciendo un menor uso del sistema de cuidados de salud. Es decir, la defensa de una sanidad pública y universal es muy importante, pero no es suficiente para reducir las desigualdades sociales en salud. Y por lo tanto, sanidad no puede ser un sinónimo de salud.

El informe Black fue un importante impulso para miles de estudios posteriores, a partir de los cuales se ha ido perfilando un cuerpo teórico sobre el concepto de las desigualdades sociales en salud, sobre su génesis y sobre las mejores vías para abordarlas.

\section{Qué entendemos actualmente por desigualdades sociales en salud}

La hipótesis básica (que, aunque bastante antigua, desgraciadamente todavía es necesario defender, demostrar y propagar) es que las enfermedades 'no caen del cielo', no se distribuyen por azar, sino que están profundamente determinadas por la estructura social, política y económica en la que vivimos.

El estudio de la distribución de la mortalidad, la discapacidad y la morbilidad, según clases sociales, género, niveles de educación, ocupación, situación de empleo, etnia, situación migratoria o áreas geográficas de residencia nos permite desvelar estos determinantes sociales de la enfermedad y poner en evidencia la debilidad científica de la ideología dominante, según la cual enfermar o morir prematuramente estaría condicionado principalmente por nuestra herencia genética, nuestros hábitos de salud libremente elegidos (no engordar, hacer ejercicio, beber con moderación, no fumar), el descubrimiento de una nueva tecnología médica o, incluso, como fruto del castigo divino o el azar. Es decir, que la salud sería prácticamente independiente de los fenómenos sociales y colectivos. Enfermar dependería del destino (determinado por la herencia, la suerte o el designio divino) o sería fruto de una decisión individual previa (cada uno sería culpable de sus propias enfermedades por 'no haberse cuidado').

$Y$ es comprensible que socialmente se imponga esta visión de la salud, pues la idea de que enfermaremos más, moriremos antes y con peor calidad de vida dependiendo del país o de la familia donde hemos nacido, el barrio donde crecemos y vivimos, o de los oportunidades de educación, trabajo o ocio que nos haya tocado tener, es muy dura... e incluso, diríamos, que es muy desestabilizadora para el mantenimiento del status quo social y político. Si aceptamos esta hipótesis, ya no es suficiente aspirar a tener acceso a un buen médico y a sofisticados recursos diagnósticos y terapéuticos hospitalarios, sino que tendríamos que luchar por una sociedad más justa, si queremos mejorar la salud de todos: la salud colectiva 0 pública. La salud pasa, de esta manera, de ser un tema médico a convertirse en un asunto ético, social y político, en el que todos tenemos algo que decir.

Puede haber diferencias y desigualdades que no son necesariamente injustas. Si alguien decide libremente ir a esquiar y se rompe una pierna, el hecho de que tenga una fractura y su hermano, que no quiso salir a esquiar, no la tenga no convierte a esa diferencia en salud en una falta de equidad en salud. $Y$ en términos colectivos, el hecho de que quienes practican deportes de riesgo tengan más accidentes tampoco se percibe como algo socialmente injusto.

Sin embargo, tener más posibilidades de enfermar por estar expuesto a un riesgo laboral (por ejemplo, enfermar por un tumor pleural por no quedarle más remedio que trabajar en un ambiente laboral expuesto al amianto) o tener una esperanza de vida menor por ser de clase trabajadora (como consecuencia de tener menores oportunidades de vida, peores hábitos de salud, mayor exposición a riesgos ambientales y laborales, vivir bajo una mayor tensión emocional e inseguridad, tener peores posibilidades de neutralizar las consecuencias de las situaciones críticas: en definitiva, por sufrir un mayor desgaste en salud) es una clara inequidad en salud.

Así pues, para que una diferencia o desigualdad en salud sea considerada una desigualdad social en salud, tienen que darse dos condiciones:

- Que se la considere socialmente injusta.

- Que sea potencialmente evitable (que haya instrumentos para haberla evitado). 
Las desigualdades sociales en salud (inequity in health) son, por tanto, las diferencias sistemáticas y potencialmente remediables en uno o más aspectos de la salud entre grupos o subgrupos de población definidos social, económica, demográfica o geográficamente. Y la investigación orientada a la equidad (equity research) es el estudio sobre la génesis y características de las desigualdades sociales en salud, con el propósito de identificar factores modificables por decisiones políticas y acciones programáticas para reducir o eliminar las desigualdades

\section{8. ¿Qué hacer? Las soluciones 'corriente arriba' o 'corriente abajo'}

Los estudios de desigualdades sociales en salud no sólo pretenden demostrar la asociación entre determinantes sociales y estados de salud, sino intervenir sobre esos determinantes para mejorar la salud de la población. Para ello, hace falta disponer de conocimientos sobre dónde y cómo intervenir. Es decir, también debemos investigar los mecanismos o vías por los que se producen las diferencias en salud, a partir de las diferencias sociales.

Una de las metáforas conceptuales más operativas es la de las soluciones 'corriente arriba' (en inglés, upstream) y 'corriente abajo' (en inglés, downstream). Sirve para conectar (y contrastar) las perspectivas más clínicas de intervención sobre el sistema de cuidados de salud con las de salud pública de intervención sobre las políticas públicas.

El proceso causal entre estratificación social y salud habría que pensarlo como un río (Figura 2), cuya fuente estaría representada por el modelo político, económico y social, que determina las reglas del acceso y distribución de la riqueza. El curso alto del río, fuertemente determinado por las características de la fuente, serían las desigualdades en oportunidades de educación, ocupación e ingresos. Éstas, a su vez, determinarían el curso medio, los llamados 'factores intermedios', una serie de determinantes (posesión de bienes materiales, factores ambientales o laborales, factores psicosociales y hábitos nocivos para la salud), distribuidos de forma diferencial entre los diferentes grupos socioeconómicos. Los bienes materiales incluyen la vivienda, el vestido, el transporte, y las posibilidades de ocio o de ayuda en caso de necesidad. El entorno urbano y ambiental en el que se vive o la exposición a riesgos laborales donde se trabaja son también factores intermedios muy influyentes. Los factores psicosociales incluyen la mediación del estrés a través de mecanismos biológicos (carga alostática), como la liberación de adrenalina (por vía simpático-adrenal) y cortisol (por el eje hipotálamo-hipofisiario-adrenal), que tienen importantes efectos en varios órganos y una demostrada influencia en mecanismos tan importantes para la salud como la tensión arterial, la coagulación sanguínea y la inmunidad. También la cohesión social y el grado de confianza mutua de la comunidad en la que se vive.

Ejemplos de intervenciones o soluciones 'corriente arriba’ o ‘corriente abajo’ serían:

a. En el manantial del río: cambios en las reglas de acceso y distribución de la riqueza, o en las prioridades del gasto público.

b. En el curso alto del río: aumento de las oportunidades de empleo, abolir el empleo precario, prevenir el fracaso y abandono escolar, o reducir la pobreza.

c. En el curso medio del río: acceso a vivienda de calidad, intervenciones de psicohigiene (promoción de la salud mental y prevención de la enfermedad mental), aumento de la cohesión social (a través de voluntariado, asociacionismo, participación social) o cambio de conductas nocivas en grupos desfavorecidos (a través de la promoción de la salud).

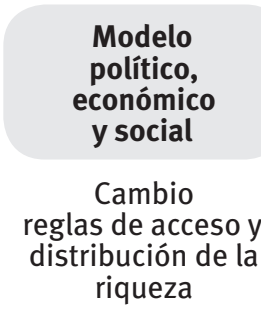

Cambio prioridades gasto público

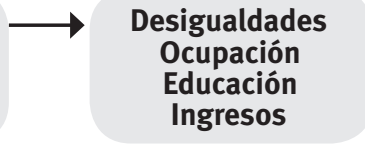

Aumentar oportunidades empleo

Abolir empleo precario

Prevenir fracaso y abandono escolar

Reducir pobreza

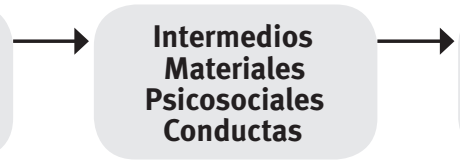

Acceso vivienda calidad

Psicohigiene

Voluntariado, asociacionismo, participación

Cambio de conducta desfavorecidos (EPS) 
d. En el tramo final (cuando la mala salud ya está presente): mejora de los cuidados de salud a los desfavorecidos (por ejemplo, eliminar barreras de acceso a los servicios sanitarios).

Las soluciones 'corriente arriba' serían más difíciles, pero teóricamente más eficaces, al incidir sobre más factores, o sobre factores con mayor potencialidad causal. Sin embargo, estos factores son menos o nada dependientes del sector sanitario, sino que son modificables por políticas públicas fiscales, educativas, laborales, de empleo, de vivienda, urbanísticas, medioambientales o sociales. Por el contrario, las soluciones 'corriente abajo' son más fáciles o sencillas, aunque nunca podrán eliminar el problema de origen. Son, además, más dependientes del sector sanitario (promoción de la salud, reforma de los servicios asistenciales).

\section{Las grandes polémicas}

El resultado de las investigaciones sobre equidad y salud, y los diferentes modelos sobre la génesis de las desigualdades sociales en salud han llevado a polémicas sobre cuáles son las vías más eficientes para intervenir en la reducción de esta brecha social de la salud. Intentaremos resumir algunas de estas polémicas, frecuentemente presentadas en forma de dicotomías excesivamente simplificadoras.

\subsection{Factores materiales frente a factores psicosociales}

Una de ellas se pregunta si, a la hora de abordar los llamados factores intermedios, debemos concentrarnos en eliminar la privación material (los factores materiales: ingresos, viviendas, vestimenta, vehículo) o si son los factores psicosociales (prestigio y estatus social, capacidad de afrontar el estrés, nivel de control en el medio laboral) los elementos fundamentales a considerar (Figura 3).

En muchos estudios, el efecto causal de la posición socioeconómica sobre el estado de salud se considera indirecto, mediado a través de una serie de determinantes que están distribuidos de forma diferencial entre los diferentes grupos socioeconómicos. Algunos de estos determinantes ya los hemos analizado, como los factores materiales, o los hábitos o conductas nocivas. Sin embargo, algunos investigadores dan más importancia a los factores psicosociales como importante contribución a las desigualdades sociales en salud.

Las clases más desfavorecidas tendrían una mayor susceptibilidad general a las enfermedades, al tener que enfrentarse a situaciones de estrés psicosocial que, mediante su repercusión en mecanismos fisiológicos y conductas, pueden favorecer la enfermedad. Así, en el medio laboral los modelos de demanda y control de Karaseck (1998) predicen que puestos de trabajo con un alto nivel de demanda y un limitado campo de decisión o control (por ejemplo, un bajo nivel de autoridad) llevan a experiencias estresantes y a mayor riesgo de cardiopatía isquémica. Estos puestos de trabajo son más frecuentes entre la clase baja.

Como es obvio, no son mutuamente excluyentes: el prestigio/estatus social bajo o la falta de control, que son etiquetados como factores psicosociales, 'se disparan' frecuentemente por factores materiales (falta de ingresos o mala vivienda). Por otra parte, los recursos materiales de alguna relevancia en la vida cotidiana tienen asociado un significado psicosocial: ser propietario de vivienda tiene implicaciones materiales, pero también representa cierta seguridad. ¿Tiene sentido preguntar o investigar qué mecanismo es más importante para explicar las desigualdades sociales en salud e intervenir sobre ellas, si la solución en ambos casos pasa por mejorar el acceso

Figura 3. Los factores intermedios

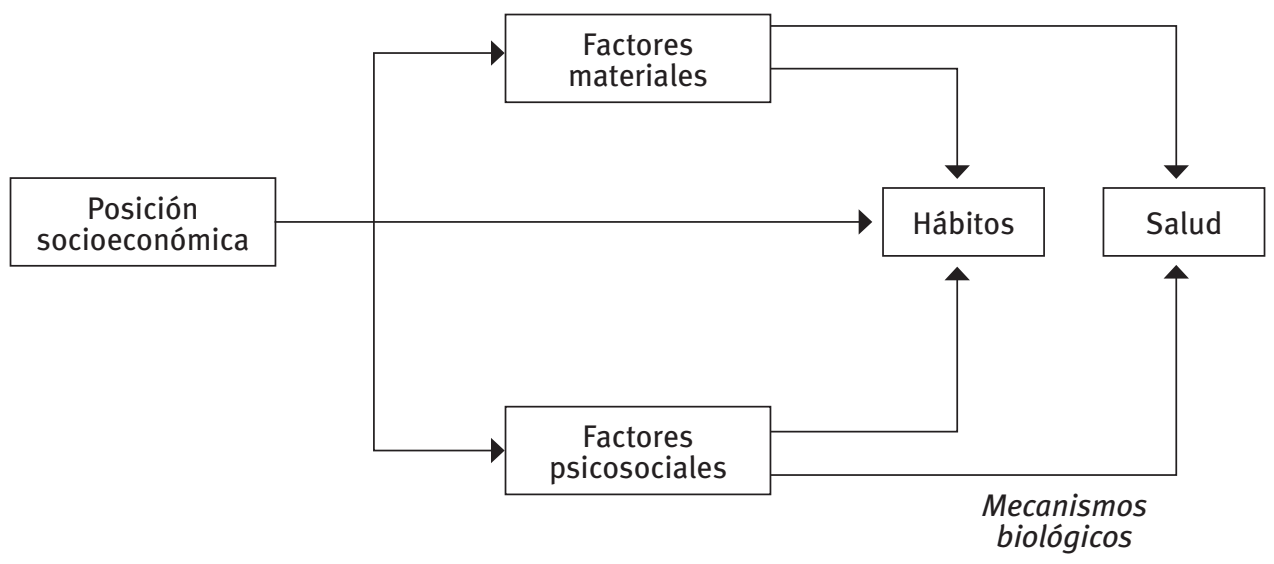

Fuente: Mackenbach (2002). 
de la población a los recursos tangibles, a la vez que se empodera a los más vulnerables (fruto de una desigualdad transgeneracional) para enfrentarse a las condiciones de vida y situaciones potencialmente patógenas?

\subsection{Desigualdad absoluta o desigualdad relativa}

Muy ligada a la anterior polémica es aquella que plantea si es más importante la desigualdad absoluta o la desigualdad relativa. Esta última se refiere a la distancia de posición social y riqueza entre los más ricos y más pobres en un país, región o vecindario, independientemente del nivel de riqueza absoluta de cada clase o estrato social. No sería la riqueza, sino la propia desigualdad la que explicaría las diferencias en salud.

Esta disyuntiva a veces se expresa como las hipótesis del ingreso absoluto o el ingreso relativo. En la hipótesis del ingreso absoluto, la salud individual sólo depende del propio nivel de ingreso. En la hipótesis del ingreso relativo, la salud individual depende también de los ingresos de los otros en la sociedad. El ingreso relativo depende del rango en la distribución de ingresos, de la distancia entre el ingreso individual y el ingreso medio. Si además del ingreso absoluto también importa el ingreso relativo, las personas con bajos ingresos tendrían peores resultados en sociedades más desiguales que en sociedades igualitarias. Ésta es la tesis principal de Richard Wilkinson y Kate Picket en su libro Desigualdad, un análisis de la (in)felicidad colectiva (2009). Sin embargo, hay que considerar que las sociedades más igualitarias que describe Wilkinson y con mejores resultados de salud, en el caso de Europa, corresponden con los países escandinavos, en los que al salario o ingreso directo hay que sumarle el indirecto fruto de unas prestaciones sociales importantes, que aseguran una red de protección colectiva frente a los riesgos para la salud.

\subsection{Capital social frente a capital monetario}

Por otra parte, a veces se da un gran valor a otros factores intermedios, como la cohesión social o el capital social (Putnam, 2000). Este último concepto se refiere a las conexiones entre individuos y redes sociales, y a las normas de reciprocidad y confianza resultantes. En la pasada década tuvo una gran influencia en muchos epidemiólogos sociales norteamericanos (estudios de comunidad o neighbourhood studies), como una variable explicativa de las desigualdades sociales en salud, independiente de los factores de privación material y las diferencias de clase. Las sociedades más igualitarias tendrían mayor cohesión social, mayor confianza en el vecino o vecina, y mayor orientación hacia la solidaridad, lo que permitiría que las personas en peor situación material pudiesen enfrentarse mejor a los retos de la vida cotidiana y mejorar su salud.

\subsection{Personas insanas frente a lugares insanos}

Muy relacionada con el concepto de capital social está la polémica sobre si se debe dar más o menos importancia al efecto sobre la salud del lugar o del contexto (vecindario, lugar de trabajo, región, país). Se podría enunciar como: 'No solamente importa quién eres, sino dónde vives'. En este efecto, a su vez, se podrían distinguir dos efectos:

- Colectivo: propiedades de los grupos que habitan el lugar (preponderancia de edades, clase social, etnia, nivel de ingresos).

- Contextual: infraestructuras, políticas sociales, ambiente cultural o religioso, influencias medioambientales.

Si hay variaciones espaciales en la salud, nos deberíamos preguntar si tienen una explicación composicional o contextual, es decir, si se deben a las características de los individuos que residen en el lugar o a las características del lugar, pero sin dejar de considerar las interacciones individualescontextuales. Por ejemplo, sabemos que los factores contextuales afectan más a grupos pobres que a los ricos. Es decir: 'No solamente importa quién eres, sino dónde vives..., pero dónde vives depende de quién eres'. Para poder analizar cada nivel u efecto de forma separada y tener en cuenta las interacciones, se diseñaron -y se han hecho bastante populares entre los epidemiólogos sociales- los llamados análisis multinivel, que son modelos estadísticos con variables que nos hablan de los determinantes en cada nivel.

\subsection{La perspectiva de la trayectoria vital}

Algunos modelos y esquemas sobre desigualdades sociales en salud, como los anteriormente descritos, no consideran suficientemente la importancia del tiempo. Las enfermedades generalmente ocurren como resultado de una exposición prolongada a factores de riesgo a lo largo de la historia vital (Figura 4). El estatus socioeconómico en la infancia (clase ocupacional de los padres) determina el estatus socioeconómico en la vida adulta y se ha demostrado cómo la exposición a bajos estatus socioeconómicos durante toda la vida supone mayor riesgo de enfermedad que la exposición durante una etapa de la vida. Por otra parte, muchos de los hábitos nocivos (como el tabaquismo) se han formado en la adolescencia, bajo la influencia del estatus socioeconómico de la infancia. Y se ha mostrado cómo las desigualdades sociales en las conductas nocivas son, en parte, el resultado de la adscripción diferenciada a un bajo estatus socioeconómico durante la infancia. Las desigualdades sociales en salud se deberían, pues, a un efecto acumulativo de desventajas a lo largo de la vida.

Las implicaciones de ello para las políticas públicas es que éstas deben priorizar las intervenciones sobre los niños y los jóvenes, además de cuidar especial- 


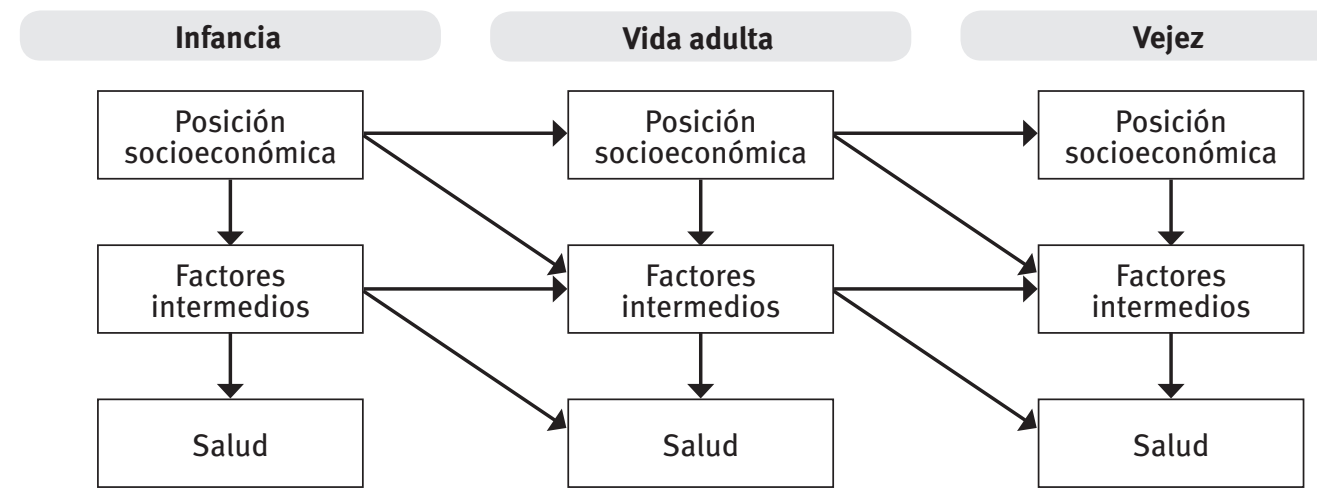

Desventaja acumulativa / Periodos críticos

Fuente: Mackenbach (2002).

mente periodos o momentos críticos de especial riesgo, tanto en edades tempranas (el nacimiento, el paso de la enseñanza primaria a la secundaria, la entrada al mercado del trabajo) como más tardías (cambios de trabajo, inicio de una enfermedad crónica, jubilación). Los sistemas de protección social tendrían el importante papel de asegurar que esos periodos críticos no resultaran en desventajas acumulativas.

\section{Las políticas para reducir las desigualdades sociales en salud en Europa}

La acumulación de evidencias a partir de múltiples estudios, como los anteriormente mencionados, y la constatación del fracaso de las políticas clásicas de salud, basadas en aumentar los recursos clínicosanitarios y en proporcionar consejos a la población, llevó a muchos países a plantearse, a finales del siglo anterior, dar un paso más en el abordaje de las desigualdades sociales en salud: pasar del estudio a la intervención. El grado de compromiso de estas iniciativas fue variable, quedándose algunas en el campo de las declaraciones programáticas y las intenciones retóricas. Además, mayoritariamente su desarrollo y sostenibilidad ha estado muy determinado por los cambios de Gobierno, o de orientación política, en los respectivos países.

Sin embargo, en el otro extremo tenemos casos en los que el empuje asociado a una firme voluntad política llevó a amplias políticas intersectoriales, refrendadas al más alto nivel (incluso parlamentario) y con una importante inversión económica asociada, y que alcanzaban los determinantes sociales estructurales de las desigualdades sociales en salud (distribución de la renta, políticas de empleo y de salario). En ocasiones, estas políticas se comprometían a ser evaluadas por fuentes independientes y mediante indicadores de salud objetivables. En unos pocos casos, las políti- cas han sobrevivido, al menos, dos legislaturas. Por desgracia, gran parte de los documentos que disponemos para revisar estas políticas de reducción de las desigualdades sociales en salud están escritos en inglés y privilegian, de nuevo, al conjunto de países del área lingüística anglosajona (Reino Unido, Irlanda, países escandinavos, Países Bajos, Canadá, Australia, Nueva Zelanda) y, en menor medida, a Alemania y Francia. Hay muy escasa información de los países latinos europeos y del este de Europa, y menos de los del resto del mundo. Ya hemos mencionado lo infrarrepresentadas que están en la literatura de salud pública mundial las interesantes experiencias de medicina social en Latinoamérica.

De cualquier forma, independientemente de este claro sesgo en relación a la cultura y lengua dominantes, no dejan de destacar, por su interés, las experiencias del Reino Unido y de los países escandinavos. La primera, porque se basa en una rica tradición de salud pública y de interés por las diferencias sociales en salud. La persistencia en el poder de los Gobiernos laboristas durante más de trece años ha permitido la sostenibilidad de un proyecto ambicioso de reducción de las desigualdades sociales en salud, que tiene el principal atractivo de que está bien documentado y se fijó metas evaluables. Por todo ello, posee un enorme valor pedagógico, tanto para las personas que se acercan al tema, como para las que lo estudian desde hace años. Y la segunda, por las políticas públicas en materia de reducción de las desigualdades que desarrollaron las socialdemocracias nórdicas en las últimas décadas. Nos detendremos en ambas experiencias, especialmente en la del Reino Unido.

Las diferencias entre unas y otras políticas se podrían resumir en cuatro aspectos (Hogstedt et al., 2008; Esnaola, 2009a):

- Orientación hacia las poblaciones más desfavorecidas (pobres o grupos sociales específicos o más 
vulnerables: minorías étnicas, madres solteras, excluidos, adolescentes embrazadas) o hacia todo el gradiente social. En el Reino Unido, tuvo un original enfoque 'geográfico', a medio camino de la dicotomía anterior: se centró en las áreas más deprimidas. Finlandia, Noruega y Suecia optaron por el enfoque de gradiente social, mientras que Dinamarca, Países Bajos e Irlanda lo hicieron por centrarse en los grupos más desfavorecidos.

- Énfasis en los estilos de vida o en los determinantes sociales estructurales: los países que optaron por el enfoque de gradiente social fueron los mismos que ambicionaban cambiar los determinantes estructurales mediante políticas de distribución de la renta, de empleo, de mejora del salario directo e indirecto, o de apoyo para la integración social y el éxito escolar, entre otras medidas. El resto se centraron más en políticas de control del tabaco, el alcohol o la ansiedad, y de promoción de la nutrición sana, el ejercicio físico o de la salud sexual de los jóvenes, aunque muchos de ellos con un abordaje complejo, que incluía las desigualdades sociales en salud en la intervención sobre los estilos de vida.

- El nivel de compromiso político: desde limitarse a ser una prioridad de un departamento de la administración de salud, pasando por ser un compromiso de gobierno de carácter interdepartamental (abarcando varios ministerios no sanitarios) -como ha sido el caso de Inglaterra-, hasta contar con el apoyo parlamentario (que incluye a la oposición política), como ocurrió en Suecia.

- El nivel de enunciación de las metas en términos cuantitativos y de evaluación. Esto sólo era posible en Inglaterra, Irlanda, Países Bajos y Finlandia.

\section{La evaluación de la experiencia inglesa (1999-2010)}

Durante la primera década del siglo, Inglaterra ha destacado por una actividad febril en materia de desigualdades sociales en salud y un compromiso político explícito en abordarlas. Aunque se pueda considerar imperfecta, y que ya tenía un precedente en una orgullosa tradición previa de más de dos siglos de abogacía de salud pública sobre la pobreza y las desigualdades sociales en salud, el desarrollo de la última década ha supuesto un hito histórico, por alcanzar un alto nivel de estructuración como estrategia nacional e intersectorial en las políticas públicas, como nunca se había visto antes.

La experiencia inglesa de reducción de las desigualdades sociales en salud se recoge en el capítulo firmado por Margaret Whitehead y Philippa Bird en Health for All? (Whitehead y Bird, 2008). Las lecciones aprendidas que exponen las autoras son interesantes, pues hablan de oportunidades, riesgos y derivas a la hora de seleccionar y aplicar las estrategias de desigualdades sociales en salud, que podrían ser del ámbito de toda Europa, incluido nuestro Estado. Se pueden resumir en los siguientes puntos:

- Los desarrollos demuestran que se pueden conseguir logros con la voluntad política, más allá del uso retórico de las desigualdades sociales en salud.

- La experiencia demuestra que cuando la voluntad política se inclina por la acción, los salubristas tienen que estar preparados para contribuir con soluciones. Los políticos demandan respuestas a sus preguntas sobre lo que puede hacerse con los problemas. Entonces se hace patente la escasez de la evidencia sobre la eficacia de las políticas e intervenciones concretas. Esto supone la necesidad urgente de promocionar estudios de evaluación sobre intervenciones complejas de salud pública y de sintetizar la experiencia disponible.

- La experiencia inglesa aporta un ejemplo de lo que pasa cuando se trata de implementar estrategias de amplio espectro. A medida que se desarrollaba el proyecto, ha habido un estrechamiento de los horizontes de la estrategia. El abordaje amplio sobre los determinantes sociales de la salud, por el que se abogaba en el informe Acheson de 1998, fue claramente reflejado en las primeras declaraciones ministeriales y en la primera estrategia de salud pública, Saving Lives, publicada en 1999 (Department of Health, 1999). Sin embargo, cuando se realizó el informe del Tesoro (Treasury Review), en 2002, y se diseñó la consecuente estrategia en 2003 , ya se vislumbraba una tendencia a enfocarse hacia proyectos específicos, diseñados para grupos socialmente desaventajados. Son más fáciles de obtener evaluaciones a escala relativamente pequeña de intervenciones individuales que evaluaciones de políticas sociales amplias. Es más fácil vislumbrar acciones sobre el tabaquismo y la actividad física que sobre determinantes situados más 'corriente arriba'.

- Ha sido notable el énfasis sobre la privación social, en detrimento del enfoque de gradiente social, ligado a las iniciativas que tenían su diana en áreas pequeñas especialmente necesitadas. Hay un problema particular de pobreza en Inglaterra que merece concentrar esfuerzos para resolverlo. Además, la pobreza se ha concentrado geográficamente en áreas pequeñas, lo que justifica dedicar recursos extraordinarios y esfuerzos para acercar dichas áreas, identificadas como especialmente necesitadas, a la situación media del país. Sin embargo, existe el peligro de concentrarse demasiado intensamente en esta estrategia de área. Uno de los problemas es que hay más gente pobre viviendo fuera que dentro de ellas y, por ello, no se beneficiarían de esta estrategia. También es deseable que se aborden las desigualdades sociales en salud presentes a lo largo de toda la escala social, lo que no se conseguirá poniendo exclusivamente el foco en los más necesitados. 
- Las metas basadas en la cuantificación de la mortalidad han resultado problemáticas. No está claro cómo fueron concebidas las metas cuantificadas de mortalidad infantil y esperanza de vida, pero se optó por indicadores relativos. La monitorización de éstos a lo largo del tiempo ha llevado a problemas de interpretación. En términos relativos, las desigualdades de ciertos indicadores han aumentado, al mismo tiempo que las diferencias absolutas han disminuido.

- Por último, debemos destacar las fuerzas que han trabajado en contra de los esfuerzos para reducir las desigualdades sociales en salud. Algunas de ellas se han concentrado especialmente en los conflictos sobre los recursos. Cuando, por ejemplo, la rama asistencial (curativa) del NHS tiene dificultades financieras, los fondos disponibles son desviados a necesidades más inmediatas. Así, disminuir las listas de espera quirúrgicas aparece como prioritario sobre metas a largo plazo 'más imprecisas' ('más blandas') dirigidas a la salud de la población. También se han desarrollado tendencias neutralizadoras en otros sectores, como el empleo, el comercio y la agricultura, que operan en contra de los deseados cambios en los determinantes de salud. Se necesitará una estrategia de vigilancia continua para asegurar que la estrategia de desigualdades sociales en salud siga activa.

\section{Las desigualdades sociales en salud, una preocupación a escala mundial}

Si el informe Black de 1980 marcó un antes y un después en la epidemiología social, el informe de la Organización Mundial de la Salud (OMS) de 2008 fue la culminación de varias décadas de esfuerzos por que el tema de las desigualdades sociales en salud llegara a las agendas políticas internacionales. La Comisión de Determinantes Sociales de la Salud (CDSS) de la OMS nació como fruto del encargo de la $57^{\underline{a}}$ Asamblea Mundial de la Salud, de mayo de 2004, de recoger las evidencias sobre las desigualdades sociales en salud y de hacer propuestas para abordarlas. La Comisión, dirigida por Michael Marmot y su equipo de la University College London, reunió un amplio panel de expertos, políticos, organizaciones y líderes sociales, con personalidades de la talla del expresidente de Chile Ricardo Lagos, el senador italiano Giovanni Berlinguer y el premio nobel de Economía Amartya Sen.

El trabajo se organizó en nueve redes de conocimiento (conocidas en inglés como knowledge networks) o grupos de investigación sobre otras tantas cuestiones: desarrollo infantil, condiciones de empleo, globalización, sistemas de salud, medio ambiente urbano, métodos, género, exclusión social y prioridades de salud pública. Su tarea era resumir las evidencias disponibles, hacer recomendaciones y ayudar a los comisionados a escribir el informe final. Éste fue presentado más de tres años después (el 28 de agosto de 2008) a Margaret Chan (la nueva directora de la OMS).
El informe final de la CDSS (2008) tenía 246 páginas, organizadas en 6 apartados y 17 capítulos, y su título fue traducido en su versión resumida castellana como Subsanar las desigualdades en una generación: alcanzar la equidad sanitaria actuando sobre los determinantes sociales de la salud.

El informe de la OMS fue un espaldarazo a los estudios y las políticas de reducción de las desigualdades sociales en salud y a la propia epidemiología social. Después de un tiempo en que esta rama de la epidemiología era marginal al sistema disciplinarioacadémico dominante, ahora parece que está de moda. No sólo se publican cada vez más estudios de este tipo en las revistas científicas y hay más interés por ellos entre los jóvenes epidemiólogos, sino que ese interés empieza a extenderse a los gobernantes. Una muestra es la incorporación del análisis de situación de las desigualdades sociales en salud, y de objetivos de reducción de éstas, en algunas agendas políticas europeas, nacionales, regionales y locales. También que el enfoque de determinantes sociales de la salud, junto con el de igualdad de género, sean elementos valorados a la hora de financiar proyectos de investigación con fondos europeos. En nuestro país, tuvo una importante influencia en el estudio que ahora veremos, impulsado por el Ministerio de Sanidad y Política Social, y en iniciativas similares de algunas comunidades autónomas y ayuntamientos.

\section{La epidemiología social en España}

En España, se ha intentado en diferentes momentos históricos de las últimas décadas aprovechar los vientos a favor de los estudios en intervenciones sobre las desigualdades sociales en salud que venían del Reino Unido (informe Black) en los años ochenta $y$, más recientemente, de la OMS (informe de la CDSS). Además hay que señalar el progresivo avance de la epidemiología social en el mundo epidemiológico español.

No es conocido por muchos el hecho de que, en España, también tuvimos un informe Black, es decir, un informe cómo resultado de una comisión oficial de estudio sobre las desigualdades sociales en salud promovida por el Gobierno de turno, estudio finalizado en 1996 y bautizado como informe Navarro. Sin embargo, al contrario que en el Reino Unido, no tuvo un gran impacto mediático ni generó un debate nacional entre las fuerzas políticas, sindicales y científicas de nuestro país. Por ello, y por las circunstancias políticas que lo rodearon en 1996, no se tradujo en intervenciones para mitigar las desigualdades sociales en salud que sacó a la luz. El informe se tituló Desigualdades sociales de salud en España. Informe de la Comisión Científica de estudios de las desigualdades sociales de Salud en España y fue publicado en la Revista Española de Salud Pública (Navarro López y Benach, 1996).

Cabe destacar que, en las últimas dos décadas, se han editado una serie de atlas de mortalidad que han con- 
seguido describir la distribución del riesgo de morir a causa de las principales enfermedades y problemas de salud, por unidades geográficas cada vez más pequeñas y socialmente más significativas. La mayoría han sido iniciativa de dos grupos de investigadores: uno en Barcelona, liderado por Joan Benach; y otro en Madrid, liderado por Gonzalo López Abente. Además, ambos impulsaron posteriormente el proyecto MEDEA (Desigualdades Socioeconómicas y Medioambientales en la Mortalidad en Ciudades de España) ${ }^{11}$, liderado por Carme Borrell, que produjo nuevos atlas que profundizaron en el trabajo previo. De los atlas por comunidades autónomas o por provincias, hemos pasado a los atlas municipales, y de éstos, a los atlas por distritos urbanos o secciones censales.

Las diferencias en la distribución geográfica de los riesgos nos han permitido analizar las desigualdades sociales, no sólo porque reflejan las diferenciales sociales, económicas y ambientales entre las regiones españolas, sino porque dentro de las ciudades, el lugar de residencia está fuertemente determinado por la pertenencia a una clase social y la capacidad de compra de la vivienda. Por desgracia, nuestras ciudades siguen estando intensamente segmentadas desde el punto de vista social.

MEDEA ha sido un proyecto de varios grupos de investigación españoles, coordinados desde la Agència de Salut Pública de Barcelona y financiados por el Fondo de Investigaciones Sanitarias (FIS). Lo destacamos no sólo por la rica producción científica que ha proporcionado, sino por haber sido una plataforma de enlace y apoyo mutuo de los grupos de investigación sobre epidemiología social, dispersos por España, y no siempre adecuadamente reconocidos y apoyados por las respectivas administraciones públicas. En Euskadi, destaca el liderado por el epidemiólogo vasco Santiago Esnaola (Esnaola, 2009b), del Departamento de Salud del País Vasco. Este grupo creó recientemente una web, Osagin-Salud Poblacional ${ }^{12}$, que ofrece una información exquisita -en presentación gráfica y en contenidos- sobre determinantes de salud, desigualdades y acciones intersectoriales en Euskadi.

Al poco de salir a la luz el informe de la CDSS de la OMS y de iniciarse la segunda legislatura del Gobierno socialista del presidente Zapatero, en octubre de 2008, la Dirección General de Salud Pública del Ministerio de Sanidad y Política Social puso en marcha una Comisión para reducir las desigualdades en salud. Era de nuevo un grupo de trabajo multidisciplinar, coordinado esta vez por Carme Borrell (y en el que el autor de este artículo tuvo el honor de participar con otros epidemiólogos antes citados, entre los que se encontraban Joan Benach y Santiago Esnaola), con el mandato de elaborar, partiendo del conocimiento existente en nuestro país, un documento con medidas de intervención a corto, medio y largo plazo para disminuir las desigualdades sociales

\footnotetext{
${ }^{11}$ 〈http://www.proyectomedea.org/medea.html)〉.

${ }^{12}$ 〈http://www.osakidetza.euskadi.net/r85-phosago1/es〉.
}

en salud en el ámbito de la salud pública, además de identificar otras áreas de intervención e instituciones implicadas en el desarrollo de aquéllas.

El informe fue presentado durante la presidencia española de la UE del primer semestre de 2010, y se titula Avanzando hacia la equidad. Propuesta de políticas e intervenciones para reducir las desigualdades sociales en salud en España (Ministerio de Sanidad y Política Social, 2010). De nuevo (informe Black, informe Navarro-Benach), el producto de la Comisión salió en un momento político y legislativo difícil para que se implementaran las políticas recomendadas. La crisis financiera, los modelos y las prioridades sobre políticas de ajuste aplicadas y la presión para disminuir el gasto social han dejado las políticas de reducción de las desigualdades sociales en salud en un segundo plano y con un escaso margen de maniobra. Esperemos que sea una situación coyuntural y que la tozudez de los datos, los estudios y los informes sobre desigualdades sociales en salud, como los que hemos ido presentando hasta ahora, vuelvan a convencer a los políticos, especialmente a aquéllos con responsabilidades de gobierno, de que la riqueza, el bienestar social y la salud de un país no se pueden conseguir a menos que se reduzca la brecha de las desigualdades sociales.

\section{Líneas futuras de investigación y acción sobre las desigualdades sociales en salud}

Con el camino recorrido hasta aquí, ya hay un cierto consenso sobre hacia dónde debemos dirigir nuestras investigaciones en desigualdades sociales en salud. El principal acuerdo es la certeza de que ya tenemos mucha información y de que ha llegado la hora de actuar. El epidemiólogo social debe pasar de la base de datos a la intervención sobre el terreno. Se deben primar las experiencias de intervención sobre las desigualdades sociales en salud. Especialmente, aquellas que aspiran a ser evaluadas y que, por lo tanto, generarán un conocimiento contrastable y útil, más allá del territorio donde se aplicaron. A pesar de que hay una rica literatura sobre la naturaleza de las desigualdades sociales en salud, se ha hecho mucho menos esfuerzo en investigar cómo intervenir sobre el problema. Como decía Margaret Whitehead en el trabajo de Health for All? (Whitehead y Bird, 2008), nos hacen falta:

- Evaluaciones sobre el impacto diferencial de intervenciones de salud pública en distintos grupos sociales. Demasiado frecuentemente, las evaluaciones pasadas se han centrado en el impacto general, controlando por estatus socioeconómico, en vez de estratificar por esta variable. Esto se ha dado incluso en campos relativamente bien investigados, como el control del tabaquismo. Con sólo un pequeño esfuerzo extra, se podría incorporar este análisis diferencial de impactos en evaluaciones ya financiadas.

- Investigaciones metodológicas para desarrollar vías de evaluación de un conjunto de interven- 
ciones o 'sistemas de políticas públicas'. Abordar las desigualdades sociales en salud requiere de combinar intervenciones más que de iniciativas aisladas, pero queda la interrogante sobre cuáles funcionan mejor en combinación y para qué grupos sociales.

- Investigaciones que utilicen más 'experimentos naturales políticos', con el fin de ayudar a evaluar el impacto sobre la salud y las desigualdades sociales en salud de políticas públicas más amplias. Esto forma parte de una demanda de hacer un mayor esfuerzo sobre cómo se deben abordar mejor los determinantes sociales de la salud, donde la evidencia disponible es particularmente escasa. Es un área madura para análisis comparativos entre países, que aporten enseñanzas en política internacional.

Por otra parte, tenemos que revisar nuestras clasificaciones de clase social, a la vista de los cambios sociales que vivimos en el siglo XXI, e incorporar mejor el eje de la desigualdad por la situación de empleo. Entre los retos a este respecto, están:

- Repensar la agrupación de clases manuales frente a las no manuales, a la vista del peso que tienen las actividades de servicios (no manuales) en las clases bajas.

- Considerar la multidimensionalidad de la identidad ocupacional. Cada vez son más frecuentes los itinerarios personales en los que se simultanean diferentes ocupaciones o en lo que se transita por varias de ellas a lo largo de una vida.

- Considerar las condiciones de empleo como un determinante muy 'corriente arriba' de las desigualdades sociales en salud, que determina no solamente las condiciones de trabajo (los clásicos riesgos laborales) y los 'factores intermedios' de las desigualdades sociales en salud (bienes materiales, riesgos residenciales y ambientales, riesgos psicosociales, hábitos de salud), sino la propia posición socioeconómica (de forma bidireccional, ya que el riesgo de ser precario o parado está, a su vez, determinado por la clase social de origen).

- Captar los extremos (y los márgenes) de la pirámide social. Corremos el riesgo de retratar sólo a la clase media (con sus diferentes matices y grados). Debemos esforzarnos en captar, en nuestros estudios y clasificaciones de clase social (muy basados en la ocupación y, más concretamente, en la ocupación estable y única a lo largo de la vida), a los excluidos del mercado de trabajo. Debemos intentar captar las múltiples caras del precariado, las nuevas formas de opresión. Tampoco debemos renunciar a retratar a 'la clase alta de la clase alta'.

- Estudiar el efecto acumulativo y sinérgico de los factores de la multivulnerabilidad social frente a la salud. ¿Qué pasa cuando se entrelazan factores como ser mujer; ser joven; ser inmigrante; pertenecer a una familia monoparental; tener la vivienda pagada o hipotecada; tener un tipo de contrato o no tenerlo; tener uno, dos o ningún sueldo en la familia? ¿Cómo integramos estos factores en nuestros estudios? ¿Como factores independientes? ¿Qué agrupaciones hacemos para el análisis?

\section{Los límites de la epidemiología social y de sus medidas}

Aunque la epidemiología social tiene vocación de construir un nuevo paradigma científico (Kuhn, 2001) que supere el dominante (Susser y Suser, 1996; Krieger, 1994), sus esquemas de pensamiento y su metodología están anclados en la epistemología positivista y determinados por los límites de la estadística (Almeida-Filho, 200o). Como el resto de 'ramas' de la epidemiología, opera con un objetomodelo (Bachelard, 2003) específico, como es el riesgo, y sobre un campo complejo, como es el social (Segura del Pozo, 2006).

La epidemiología social practica una epidemiología observacional, que difiere de la orientación experimental de la epidemiología clínica, basada principalmente en ensayos clínicos, donde el campo de investigación se recorta a una selección de variables de interés clínico de grupos de pacientes aislados de su medio social. Sin embargo, no nos olvidemos que, aunque la epidemiología observacional tiene vocación de estudiar la realidad de forma lo más inclusiva posible, algunos autores (Almeda-Filho, 2004) advierten del riesgo de estar construyendo conocimientos a partir de la relación con un mundo virtual, en el que las bases de datos sustituyen a las poblaciones reales y las operaciones estadísticas y las estimaciones de los perfiles de riesgo con vocación de universalidad sustituyen la escucha de la población y dificultan captar toda la riqueza del complejo proceso de salud y enfermedad.

Otro riesgo de la epidemiología social sería su aislamiento de la realidad social, al estar sus investigadores frecuentemente alejados del campo de la intervención en salud pública (que incluye la llamada epidemiología de campo) En el caso de los epidemiólogos sociales, cuyos principales mentores abogan por la socialización del epidemiólogo, el aislamiento del medio social sería una doble contradicción respecto al nombre que los identifica; por ello, deben huir de la tentación de recluirse en las 'torres de marfil' de las universidades o de los institutos de investigación, lugares donde paradójicamente es más factible hacer estudios de desigualdades sociales en salud. Por suerte, en el campo de la epidemiología social, en especial en la latinoamericana (AlmeidaFilho, 2003; Waitzkin et al., 2001), tan desconocida en nuestro país a pesar de la proximidad cultural y lingüística, se viene desarrollando la conciencia (y la práctica) de que es necesario incorporar el pensamiento complejo (Pérez Andrés, 2002) y las metodologías de investigación cualitativas para operar sobre la complejidad propia de la sociedad y las 
poblaciones, para lo que es necesario construir un nuevo paradigma que incluya categorías propias del subjetivismo, la reflexividad, el determinismo abierto y la elucidación.

La búsqueda de la brillantez metodológica deja insatisfecho a quien está permanentemente en contacto con el campo, que es el ámbito de la complejidad. Los problemas del campo de la salud pública, como problemas sociales que son, tienen difícil solución desde el abordaje profesional individual y desde el método positivista-estadístico. La realidad nunca se ajusta a los modelos, siempre faltan datos o dudamos de su calidad, muchas veces se saben perfectamente las cosas, pero parece que los datos en que uno se apoya no son suficientes o solventes. Siempre hay algo que se escapa (alguna variable forzada, alguna conclusión cogida por los pelos, algo que no acaba de ser verdad del todo). Además, se está abocado a la frustración de no tener la satisfacción de la resolución inmediata de los problemas, ni el reconocimiento social que ello genera, como ocurre en la práctica clínica, con la que están en contacto tan directo los epidemiólogos de campo. Por otra parte, los epidemiólogos sociales estarán permanentemente abocados a la frustración inherente a la dificultad de influir en las políticas públicas (Segura del Pozo, 2006).

\section{6. ¿Es posible una epidemiología (social) 'mestiza'?}

Los límites de la epidemiología social, que son los límites de la epidemiología, podrían superarse si los situamos en el método epidemiológico y concebimos la epidemiología como el área de conocimiento que estudia los factores colectivos de la salud y la práctica que contribuye a intervenir sobre ellos. Como tal, la epidemiología, al abarcar lo colectivo, sería una ciencia social. El problema aparece cuando intentamos aprehender cosas del campo colectivo y social con herramientas creadas para el campo biológico e individual, o si nos seguimos aferrando al positivismo en el siglo XXI. El valor que puede tener la epidemiología y la salud pública para la sociedad es precisamente su carácter 'mestizo', entre lo biomédico y lo social, entre lo clínico-individual y lo psicosocial-colectivo, entre lo técnico y lo político, y sus posibilidades de mediación entre ambas orillas. Desde esta apertura fuera de los limites, podríamos pensar en una 'epidemiología (social) mestiza’, fruto del mestizaje entre el enfoque de las ciencias biológicas y el de las ciencias sociales y humanas, que incluyera, por otra parte, el uso ecléctico tanto de los métodos cuantitativos como de los cualitativos, superando incluso en algunos casos esta dicotomía (Segura del Pozo, 2007). 
ACHESON, D. (1998): Independent Inquiry into Inequalities in Health. Report, Londres, The Stationery Office [khttp://www.archive.official-documents. co.uk/document/doh/ih/ih.htm〉].

ALMEIDA-FILHO, N. (2004): "Saramago's all the names and the epidemiological dream", Journal Epidemiology Community of Health, $\mathrm{n}-58$, págs. 743-746.

- (2000): La ciencia tímida: ensayos de deconstrucción de la epidemiología, Buenos Aires, Lugar Editorial.

ALMEIDA-FILHO, N. et al. (2003): "Research on health inequalities in Latin America and the Caribbean: Bibliometric analysis (1971-2000) and descriptive content analysis (1971-1995)", American Journal of Public Health, vol. 93 , no 12 , págs. 2.037-2.043 [khttp://www.ncbi. nlm.nih.gov/pubmed/14652329>].

BACHELARD, G. (2003): La formación del espíritu científico, Madrid, Siglo XXI.

BLACK, G. (1982): Inequalities in Health: Black Report, serie: Pelican, Harmondsworth; Nueva York, Penguin Books.

COMISIÓN PARA REDUCIR LAS DESIGUALDADES SOCIALES EN SALUD EN ESPAÑA (2010): Avanzando hacia la equidad. Propuesta de políticas $e$ intervenciones para reducir las desigualdades sociales en salud en España, Dirección General de Salud Pública y Sanidad Exterior Ministerio de Sanidad y Política Social [<http://www.mspsi.gob.es/profesionales/ saludPublica/prevPromocion/promocion/ desigualdadSalud/docs/Propuesta_Politicas_ Reducir_Desigualdades.pdf〉].

DEPARTMENT OF HEALTH (1999): Saving Lives: Our Healthier Nation, Londres, Stationery Office.
ESNAOLA, S. et al. (2009a): “Las políticas para reducir las desigualdades en salud en Europa", en MINISTERIO DE SANIDAD Y POLÍTICAS SOCIALES, Informe de la Comisión de Desigualdades Sociales en Salud [inédito].

- (2009b): “Desigualdades socioeconómicas en la mortalidad en el País Vasco y sus capitales: un análisis de áreas geográficas pequeñas (Proyecto MEDEA)", Estudios Geográficos, vol 70, no 267 , págs. 443-462 [rhttp:// estudiosgeograficos.revistas.csic.es/ index.php/estudiosgeograficos/article/ viewFile/125/122>].

HER MAJESTY'S TREASURY; y DEPARTMENT OF HEALTH (2002): Tackling Health Inequalities: Summary of the 2002 Cross-Cutting Review, Londres, HM Treasury.

HOGSTEDT, C. et al. (eds.) (2008): Health for All? A Critical Analysis of Public Health Policies in Eight European Countries, Estocolmo, Swedish National Institute of Public Health

KARASEK, R. (1998): "Demand/control model: A social, emotional and physiological approach to stress risk and active behavior development", en STELLMAN, J. M. (ed.), Encyclopedia of Occupational Health and Safety, Ginebra, Organización Internacional del Trabajo, págs. 34.6-34.14.

KRIEGER, N. (1994): "Epidemiology and the web of causation: Has anyone seen the spider?", Social Science and Medicine, vol. 39, $\mathrm{n}-7$, págs. 887-903.

KUHN, T. S. (2001): La estructura de las revoluciones científicas, México DF, Fondo de Cultura Económica.

MACKENBACH, J. (2002): "Socio-economic inequalities in health in developed countries: The facts and 
the options", en DETELS, R. et al. (eds.), Oxford Textbook of Public Health, Oxford Press.

MARMOT, M. G. et al. (1978): “Employment grade and coronary heart disease in British civil servants", Journal of Epidemiology and Community Health, vol. $32, \mathrm{n}$ 은 , págs. 244-249.

MINISTERIO DE SANIDAD Y POLÍTICA SOCIAL (2010): Avanzando hacia la equidad. Propuesta de políticas e intervenciones para reducir las desigualdades sociales en salud en España, Dirección General de Salud Pública y Sanidad Exterior, Ministerio de Sanidad y Política Social [<http://www.mspsi.gob.es/profesionales/ saludPublica/prevPromocion/promocion/ desigualdadSalud/docs/Propuesta_Politicas Reducir_Desigualdades.pdf $>$.

NAVARRO LÓPEZ, V.; y BENACH J. (1996): “Desigualdades sociales de salud en España. Informe de la Comisión Científica de estudios de las desigualdades sociales de Salud en España", Revista Española de Salud Pública, ํㅜ 70, págs. 505-636 [<http://www.msssi.gob.es/ biblioPublic/publicaciones/recursos_propios/ resp/revista_cdrom/VOL70/70_5_505.pdfı].

ORGANIZACIÓN MUNDIAL DE LA SALUD (2008): Closing the Gap in a Generation. Health Equity through Action on Social Determinants of Health, Ginebra, Organización Mundial de la Salud [<http://whqlibdoc.who.int/ publications/2008/9789241563703_eng.pdfs]

PÉREZ ANDRÉS, C. (ed.) (2002): “Monográfico sobre la investigación cualitativa en salud en España", Revista Española de Salud Pública, vol. 76, ํㅜ 5 .

PUTNAM, R. (2000): Bowling alone. The collapse and revival of American Community, Simon and Schuster Paperback.

ROSE, G. (1994): La estrategia de la medicina preventiva, Barcelona, Masson; Salvat.
SAN MARTíN, H. (1995): Salud y enfermedad, La Prensa Médica Mexicana [1a ed.: 1961, Cuba].

SEGURA DEL POZO, J. (2013): Desigualdades sociales en salud: conceptos, estudios e intervenciones (1980-2010), Bogotá, Universidad Nacional de Colombia, Doctorado Interfacultades en Salud Pública [<http://saludpublicayotrasdudas. wordpress.com/>].

- (2007): “Epidemiología mestiza”, Gaceta Sanitaria, vol. 21, nํㅜ1, págs. 88-88 [<http://scielo.isciii. es/pdf/gs/v21n1/carta1.pdf)].

- (2006): “Epidemiología de campo y epidemiología social”, Gaceta Sanitaria, vol. 20, n으 2, págs. $153-158$ [ [http://scielo.isciii.es/pdf/gs/ v2on2/especial.pdf>].

SUSSER, M. (1991): Conceptos y estrategias en Epidemiología. El pensamiento causal en las ciencias de la salud, México DF, Fondo de Cultura Económica.

SUSSER, M.; y SUSSER, E. (1996): “Choosing a future for epidemiology", en ALMEIDA FILHHO, N. et al. (eds.), Teoria epidemiológica hoje: fundamentos, interfaces, tendências, Río de Janeiro, Fiocruz; ABRASCO.

WAITZKIN, H. et al. (2001): "Social medicine in Latin America: Productivity and dangers facing the major national groups", Lancet, vol. 28, nํㅜ 358 , págs. 315-323.

WHITEHEAD, M.; y BIRD, P. (2008): “England”, en HOGSTEDT, C. et al. (eds.) (2008): Health for All? A Critical Analysis of Public Health Policies in Eight European Countries, Estocolmo, Swedish National Institute of Public Health.

WILKINSON, R.; y PICKET, K. (2009): Desigualdad, un análisis de la (in)felicidad colectiva, Turner. 